\title{
Characterization of Low Level Wastes: a new design for calorimetric measurement
}

\author{
Kévin Galliez, Guillaume Jossens, Alain Godot and Christophe Mathonat
}

\begin{abstract}
Calorimetry is one of the best solutions to estimate the overall quantity of nuclear material on a wide range of masses, from a few milligrams up to kilograms of radionuclides, by measuring the overall thermal power due to the radioactive decay coming from the waste contained in a metallic drum or a different type of container. It has many advantages as it features a non-destructive method which remains independent of matrix effect or the chemical composition. Until now, calorimetry allows to measure at the lowest 0.5 to $1 \mathrm{~mW}$ for samples up to 385 liters. But nowadays, thanks to new technological breakthroughs, KEPTechnologies calorimeters are able to measure as low as $50 \mu \mathrm{W}$ for 40 liters samples. The $\mu \mathrm{LVC}$ is based on a new design with twin cells, a new temperature regulation loop and a heat-flow measurement system inside a vacuum chamber (Patent deposit P005299 LA/VL). The $\mu \mathrm{LVC}$ is a differential heat-flow calorimeter for precise measurement independent of the residual fluctuations caused by environmental changes. The new calorimeter is an industrial product able to work in environmental conditions with wide temperature variations. The first results have shown a great improvement in the detection of very low thermal effect thanks to the thermal noise reduction. The paper presents the developments in Large Volume Calorimetry as a new tool for quantification of nuclear material to characterize Pu-Am samples, i-graphite, and low tritium samples with high precision and reliability.
\end{abstract}

Index Terms-calorimetry, tritium, carbone14, chlorine36, nuclear waste

\section{INTRODUCTION}

$\mathrm{R}$ ADIOACTIVE radioactive isotopes within the item. Calorimetry is used as a non-destructive assay technique to determine alpha or beta emitters inventories. It is one of the best solutions to estimate the overall quantity of nuclear material on a wide range of mass, from a few milligrams up to kilograms of radionuclides with a good precision. In the case of drums containing nuclear waste, characterization is very challenging due to complex matrix, volume and low level activities. The advantage of calorimetry towards other techniques is that the measurement is independent of the matrix, only the thermal conductivity of the sample matters, which influences the measurement time. In that case, waste

This paper has been submitted on the 1rst of June 2017.

Kévin Galliez, Alain Godot and Christophe Mathonat are from KEP Nuclear, ZA de l'Euze 2, 453 Chemin vieux de Chusclan, 30200 Bagnols sur Cèze, France (contact.nuclear@kep-technologies.com).

Guillaume Jossens is from KTHTP, 7 rue de l'Oratoire, 69300 Caluire, France (contact.htp@kep-technologies.com). can either be in solid, liquid or gas phase.

The new type of calorimeter developed by KEP Nuclear, called $\mu$ LVC (Figure 1) meaning microwatts-Large Volume Calorimeter, is able to measure less that one hundred of microwatts for a container volume of 40 liters. This paper presents the conception of this calorimeter and gives some results on the tests currently performed at KEP Nuclear.

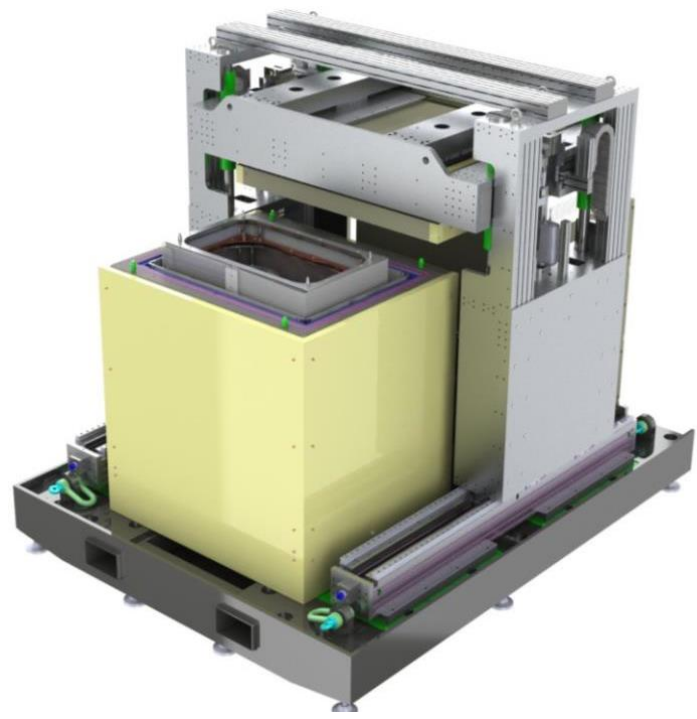

Fig. 1. 3D view of the $\mu \mathrm{LVC}$ calorimeter

The $\mu$-LVC is based on a differential heat flow calorimeter designed with twin cells, temperature sensors and heat-flow measurement system inside a vacuum chamber (Patent deposit P005299 LA/VL). Differential heat-flow calorimeters are designed with twin cells for a precise heat flow measurement. Thus, residual fluctuations caused by environmental changes are approximately cancelled out by the signal difference formed between the two cells. The calorimetric signal results from the measurement of the heat flow between the measurement cell containing the radioactive sample and the thermal block. The temperature of the thermal bloc is maintained constant thanks to resistive heater. This thermal heat flow generates a signal $(\mu \mathrm{V})$ based on time which is recorded by a data acquisition system. When the heat flow signal is stabilized, this one is converted to a thermal activity (W) by means of the linear calibration curve. The Figure 2 shows a schematic view of the calorimeter. 


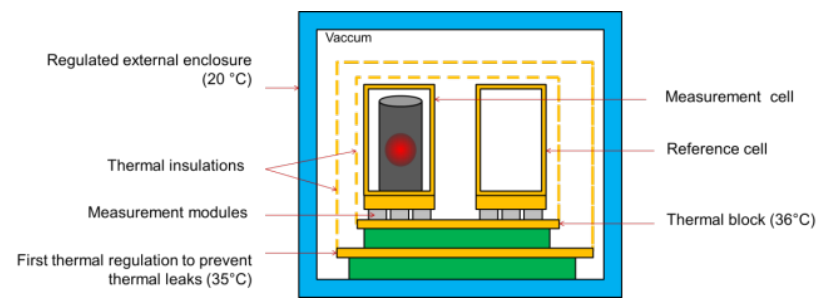

Fig. 2. Schematic view of the $\mu$-LVC

The thermal bloc is regulated using the temperature derivative sensing [1]. The heat flow between the calorimetric bloc and a mass of high thermal inertia - which serves as a reference of temperature - is regulated. The information on the heat flow is given by a thermopile installed between the reference mass and the thermal block. The signal coming from the thermopile is kept constant and close to zero in order to bring the calorimeter at its thermal equilibrium. This principle allows achieving high temperature stability and a very precise regulation. In the case of the calorimeter $\mu \mathrm{LVC}$, the reference mass is the reference cell and the calorimeter block is the thermal block (see Figure 2). The limitation of thermal leaks of the calorimeter is ensured by the use of a high vacuum $(<$ $1.10-6$ mbar) thermally regulated.

The heat flow is measured thanks to a set of Peltier modules arranged in the calorimetric block. The heat flow generated between the sample and the thermal block is thus measured and can be compared with the heat flow measured between the reference cell and the calorimetry block. The heat flow actually released by the sample is thus obtained by subtracting the flow measured on the reference cell from that measured on the measurement cell. The use of several Peltier modules for the same measurement of a heat flow makes it possible to increase the sensitivity of the measurement.

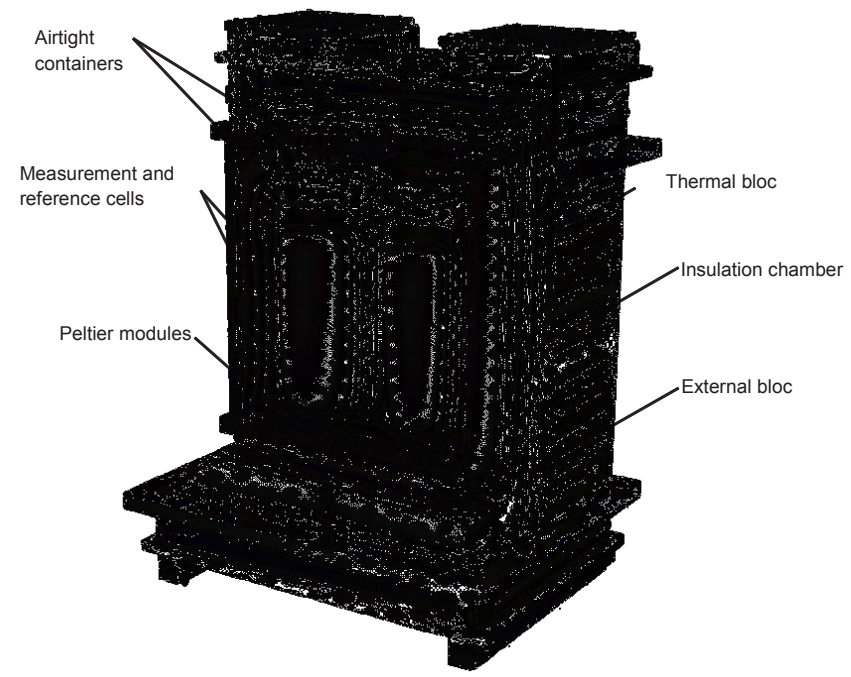

Fig. 3. Illustration of the $\mu \mathrm{LVC}$

Copper containers have been designed for the measurement of samples. The weight of a container is approximately $60 \mathrm{~kg}$. A guide and guidance arm specifically designed for the containers and cells (Figure 4) are used to place the cells in the calorimeter with an excellent reproducibility. The containers are lifted up thanks to a gantry and hoist in the testing hall.
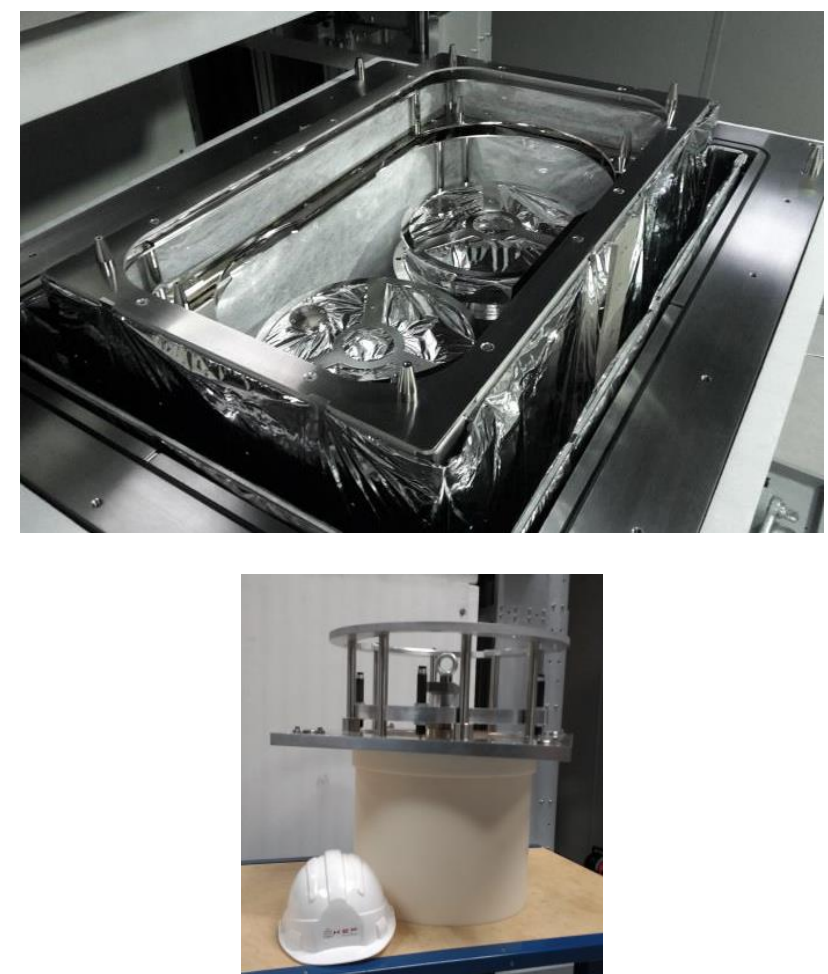

Fig. 4. Measurement and references cells in the $\mu \mathrm{LVC}$ (left). Guide and guidance arm (right)
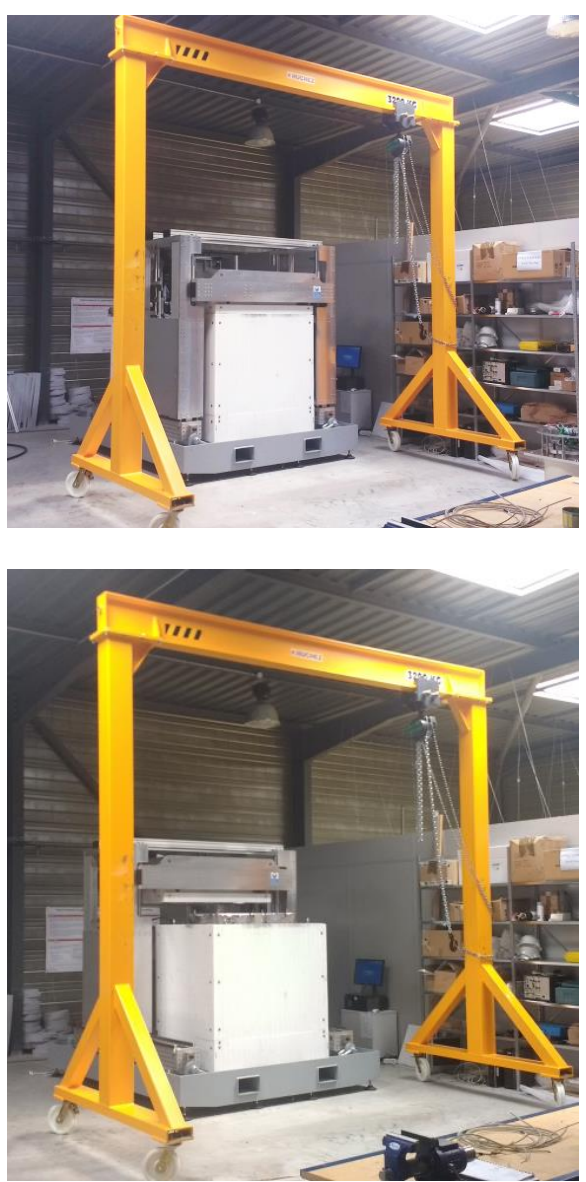

Fig. 5. closed (left) and opened (right) positions 


\section{RESULTS AND DISCUSSION}

\section{A. Calibrating the calorimeter}

\section{1) Estimating the sensitivity}

For estimating the detection limit, the sensitivity and the measurement uncertainty, the injection of a known thermal power using the integrated resistances under the cells are used. For this purpose, a 3-times repetition of a baseline and 100 $\mu \mathrm{W}$ Joule effect measurements have been done. For the repeatability assessment, the containers were withdrawn from the calorimeter between each repetition. The Figure 6 shows the stabilization of the differential heat flow measured in absence of heating (i.e. a baseline). The Figure 7 shows the signal of the differential heat flows when a power of $100 \mu \mathrm{W}$ is injected in the cells. It also shows the long term variation of the signal, slightly following the ambient temperature variation of the room. Finally the Figure 8 shows the electronic noise measured on the signal.

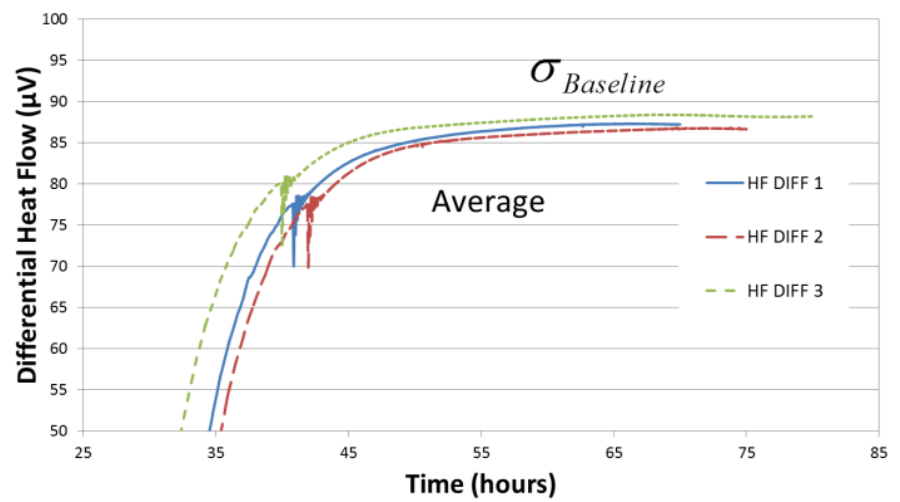

Fig. 6. Baseline of the differential heat flow

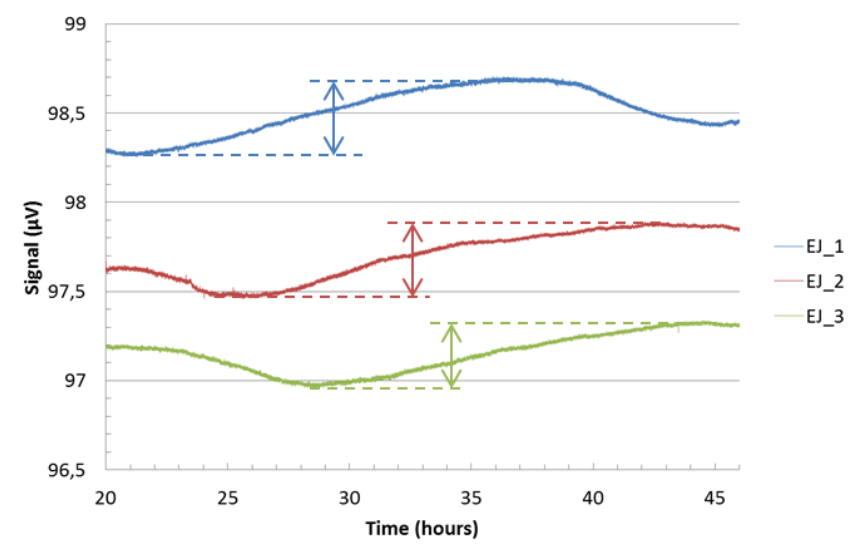

Fig. 7. Long time variations of the signal on three Joule effect measurements

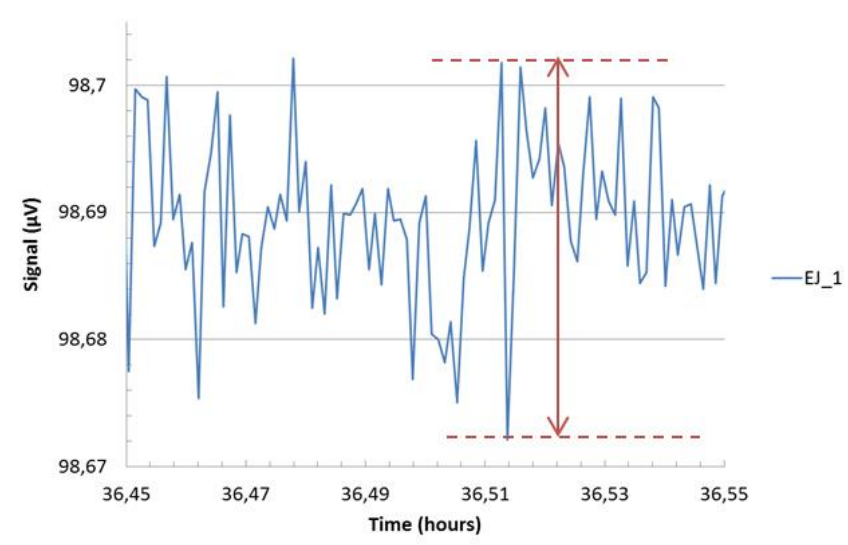

Fig. 8. Short time variation of the heat flow signal

The baselines (Figure 6) and $100 \mu \mathrm{W}$ (Figure 7) Joule effect measurements allow us to calculate the sensitivity of the calorimeter:

$$
\bar{S}=\frac{1}{3} \sum_{i=1}^{3} S_{i} \text { with } \quad S_{i}=\frac{\Delta V_{\text {mes }}-\Delta V_{\text {baseline }}}{P_{\text {injected }}}
$$

$\Delta V$ mes corresponds to the measured differential voltage during a Joule effect in $\mu \mathrm{V}$ and $\Delta$ Vbaseline corresponds to the measured differential voltage during a baseline in $\mu \mathrm{V}$. The sensitivity calculated is $105 \mu \mathrm{V} / \mathrm{mW}( \pm 2.1 \%)$. Uncertainties are calculated according to the GUM [2]. Note that the signal corresponding to the Figure 8 shows a non-predictable variation of the signal corresponding to less than $0.02 \%$ of the signal. According to the GUM [2] this error is negligible compared to the long term variation avec repetitiveness of the measurement. Indeed, the final error estimated for a $100 \mu \mathrm{W}$ power measurement is $5.6 \%(\mathrm{k}=1)$.

\section{2) Estimating the detection and quantification limit}

The detection limit is calculated according to Currie [3] using the formula:

$$
L D=\frac{\sigma_{L D B}}{\bar{S}} * 3
$$

The quantification limit is calculated according to Currie and McDougall [3], [4] using the formula:

$$
L Q=\frac{\sigma_{L D B} * 10}{\bar{S}}
$$

The standard deviation of the baseline is assessed using the Figure 6 . The calculations give a detection limit of $25 \mu \mathrm{W}$ and a quantification limit of $83 \mu \mathrm{W}$.

\section{B. Application to ${ }^{14} \mathrm{C},{ }^{3} \mathrm{H}$ and ${ }^{36} \mathrm{Cl}$}

Thanks to the Joule effect calibration module of the calorimeter, the $\mu \mathrm{LVC}$ offers the possibility to simulate a heating from tens of $\mu \mathrm{W}$ to several tens of $\mathrm{mW}$. Knowing the specific power of radionuclides, it is easy to assess the amount of radionuclides measureable using our calorimeter. Considering the three radionuclides $3 \mathrm{H}, 14 \mathrm{C}$ and $36 \mathrm{Cl}$, the detection and quantification limits are: 
TABLE I

DETECTION LIMITS FOR COMMON RADIONUCLIDES USING THE $\mu$ LVC

$$
\text { LD }
$$

LQ

\begin{tabular}{lll}
\hline $3 \mathrm{H}(324 \mathrm{~mW} / \mathrm{g})$ & $80 \mu \mathrm{g}-29 \mathrm{GBq}$ & $256 \mu \mathrm{g}-92 \mathrm{GBq}$ \\
$14 \mathrm{C}(1.32 \mathrm{~mW} / \mathrm{g})$ & $19 \mathrm{mg}-3.1 \mathrm{GBq}$ & $63 \mathrm{mg}-10 \mathrm{GBq}$ \\
$36 \mathrm{Cl}(0.06 \mathrm{~mW} / \mathrm{g})$ & $416 \mathrm{mg}-0.51 \mathrm{GBq}$ & $1.40 \mathrm{~g}-1.72 \mathrm{GBq}$ \\
\hline
\end{tabular}

These detection limits are given for samples containing only one type of radionuclide. The specific powers have been calculated using the following formula:

$$
S P(W / g)=\frac{2119.3 * Q}{T_{1 / 2}^{*} A}
$$

With:

- 2119.3 : the coefficient converting the period into second, the $\mathrm{MeV}$ into $\mathrm{J}$ and the mass number into gram.

- $\quad$ Q the average energy of the radionuclide in $\mathrm{MeV}$.

- $\quad$ the period in years.

- $\quad$ A the mass number in $\mathrm{g} \cdot \mathrm{mol}^{-1}$.

\section{CONCLUSION}

KEP Nuclear has developed a new calorimeter able to measure less than $100 \mu \mathrm{W}$ with an uncertainty lower than 10 $\%(\mathrm{k}=1)$ for a large volume container of 40 liters. The detection limit estimated for tritium, carbon 14 and chlorine 36 are respectively $80 \mu \mathrm{g}, 19 \mathrm{mg}$ and $416 \mathrm{mg}$. The $\mu \mathrm{LVC}$ truly constitutes a breakthrough in the field of calorimetry and NDA. Further tests are already planned at KEP Nuclear to improve the measurement time and the stability of the signal for improving the daily rate of analysis and the repeatability of the measurement.

\section{REFERENCES}

[1] J. L. Hemmerich, J.-C. Loos, A. Miller, and P. Milverton, "Advances in temperature derivative control and calorimetry," Rev. Sci. Instrum., vol. 67, no. 11, pp. 38773884, Nov. 1996.

[2] "Évaluation des données de mesure - Guide pour l'expression de l'incertitude de mesure," JCGM/WG 1, JCGM 100:2008(F), 2008.

[3] L. A. Currie, "Limits for qualitative detection and quantitative determination. Application to radiochemistry," Anal. Chem., vol. 40, no. 3, pp. 586-593, Mar. 1968.

[4] D. MacDougall and W. B. Crummett, "Guidelines for data acquisition and data quality evaluation in environmental chemistry," Anal. Chem., vol. 52, no. 14, pp. 2242-2249, Dec. 1980. 